\title{
Long-term Reverse Remodeling and Clinical Improvement by MultiPoint Pacing in a Randomized, International, Middle Eastern Heart Failure Study
}

\author{
AbdulMohsen AlMusaad ${ }^{1}$, Raed Sweidan ${ }^{2}$, Haitham Alanazi ${ }^{1}$, Fayez Bokhari ${ }^{2}$, Yahya S \\ Alhebaishi ${ }^{3}$, Ahmed Al Fagih ${ }^{3}$, Bandar Al Ghamdi ${ }^{4}$, Naeem Alshoaibi ${ }^{5}$, Najib Alrawahi ${ }^{6}$, \\ Ahmad Hersi ${ }^{7}$, Abdurahman Jamiel ${ }^{1}$, Amjad Al-Mandalawi ${ }^{8}$, Mohammed Hashim ${ }^{9}$, \\ Mohammad Amin ${ }^{10}$, Mohamed ElMaghawry ${ }^{11}$, Antonio Sorgente ${ }^{12}$, Maria Loricchio ${ }^{13}$, \\ Ghaliah Al Mohanny ${ }^{6}$, Ismail Al Abri ${ }^{14}$, Edmon Benjamin Khammo ${ }^{8}$, Nazar Sudan ${ }^{15}$, \\ Alexandre Chami $^{16}$, Nima Badie ${ }^{16}$, and Mohamed Sayed ${ }^{11}$ \\ ${ }^{1}$ King Abdulaziz Medical City \\ ${ }^{2}$ King Fahd Armed Forces Hospital \\ ${ }^{3}$ Prince Sultan Cardiac Center \\ ${ }^{4}$ King Faisal Specialist Hospital and Research Centre \\ ${ }^{5}$ King Abdulaziz University Hospital \\ ${ }^{6}$ National Heart Center at the Royal Hospital \\ ${ }^{7}$ King Khalid University Hospital \\ ${ }^{8}$ Ibn Al-Bitar Specialized Center for Cardiac Surgery \\ ${ }^{9}$ Nassiryia Heart Center \\ ${ }^{10}$ Bahrain Defence Force Royal Medical Services \\ ${ }^{11}$ Department of Cardiology \\ ${ }^{12}$ Cleveland Clinic Abu Dhabi \\ ${ }^{13}$ Al-Amiri Hospital \\ ${ }^{14}$ National Herat Center at the Royal Hospital \\ ${ }^{15}$ Nassiriya Heart Center \\ ${ }^{16}$ Abbott
}

May 14, 2020

\begin{abstract}
Introduction: Cardiac resynchronization therapy (CRT) with multipoint left ventricular (LV) pacing (MultiPoint Pacing, MPP) has been shown to improve CRT response, although MPP response using automated pacing vector programming has not been demonstrated in the Middle East. Objective: Compare the impact of MPP to conventional biventricular pacing (BiV) using echocardiographic and clinical changes at 6 months post-implant. Methods: This prospective, randomized study was conducted at 13 Middle Eastern centers. After de novo CRT-D implant (Abbott Unify Quadra MP or Quadra Assura MP) with quadripolar LV lead (Abbott Quartet), patients were randomized to either BiV or MPP therapy. In BiV patients, the LV pacing vector was selected per standard practice; in MPP patients, the two LV pacing vectors were selected automatically using VectSelect. CRT response was defined at 6 months post-implant by a reduction in LV end-systolic volume (ESV) [?]15\%. Results: One-hundred and forty-two patients (61 years old, $68 \%$ male, NYHA class II/III/IV 19\%/75\%/6\%, 33\% ischemic, 57\% hypertension, 52\% diabetes, $158 \mathrm{~ms}$ QRS, $25.8 \%$ ejection fraction $[\mathrm{EF}])$ were randomized to either $\mathrm{BiV}(\mathrm{N}=69)$ or $\mathrm{MPP}(\mathrm{N}=73)$. After 6 months,
\end{abstract}


MPP vs. BiV patients experienced greater ESV reduction (25.0\% vs. $15.3 \%, \mathrm{P}=0.08)$, greater EF elevation ( $11.9 \%$ vs. $8.6 \%$, $\mathrm{P}=0.36)$, significantly greater ESV response rate $(68.5 \%$ vs. $50.7 \%, \mathrm{P}=0.04)$, and significantly greater NYHA class improvement rate $(80.8 \%$ vs. $60.3 \%, \mathrm{P}=0.01)$. Conclusions: With MPP and automatic $\mathrm{LV}$ vector selection, more CRT patients in the Middle East experienced reverse remodeling and clinical improvement relative to conventional BiV pacing.

\section{Long-term Reverse Remodeling and Clinical Improvement by MultiPoint Pacing in a Ran- domized, International, Middle Eastern Heart Failure Study}

Abdulmohsen Almusaad, $\mathrm{MD}^{1}$; Raed Sweidan, $\mathrm{MD}^{2}$; Haitham Alanazi, $\mathrm{MD}^{1}$; Fayez Bokhari, $\mathrm{MD}^{2}$; Yahya Al Hebaishi, MD ${ }^{3}$; Ahmed Al Fagih, $\mathrm{MD}^{3}$; Bandar Al Ghamdi, $\mathrm{MD}^{4}$; Naeem Al Shoaibi, MD ${ }^{5}$; Najib Alrawahi, $\mathrm{MD}^{6}$; Ahmad Hersi, $\mathrm{PhD}^{7}$; and other Members of the Quadra MPP ME Group

\section{Author Affiliations:}

1. King Abdulaziz Medical City - National Guard Health Affairs, Riyadh, Kingdom of Saudi Arabia

2. King Fahad Armed Forces Hospital, Jeddah, Kingdom of Saudi Arabia

3. Prince Sultan Cardiac Center, Riyadh, Kingdom of Saudi Arabia

4. King Faisal Hospital and Research Center, Riyadh, Kingdom of Saudi Arabia

5. King Abdulaziz University Hospital, Jeddah, Kingdom of Saudi Arabia

6. National Heart Center at the Royal Hospital, Muscat, Oman

7. King Khalid University Hospital, Riyadh, Kingdom of Saudi Arabia

Brief Title: Reverse Remodeling by MultiPoint Pacing in the Middle East

Word count: 4,536

Funding Sources: This study was funded by Abbott.

Conflicts of Interest: Najib Al Rawahi, Fayez Bokhari, Raed Sweidan, Ahmed Al Fagih, Yahya Al Hebaishi, Ahmed Al Fagih, Ahmad Hersi, Naeem Al Shoaibi, and Maria Loricchio received research grants and/or consultancy fees from Abbott. Alexandre Chami and Nima Badie are employees of Abbott.

Corresponding Author: Abdulmohsen Almusaad, MD King Abdalaziz Medical City

National Guard Health Affairs

Riyadh, Kingdom of Saudi Arabia

Telephone: +966503231833

E-mail: a_almusaad@yahoo.com Abstract

Introduction : Cardiac resynchronization therapy (CRT) with multipoint left ventricular (LV) pacing (MultiPoint Pacing, MPP) has been shown to improve CRT response, although MPP response using automated pacing vector programming has not been demonstrated in the Middle East.

Objective: Compare the impact of MPP to conventional biventricular pacing (BiV) using echocardiographic and clinical changes at 6 months post-implant.

Methods : This prospective, randomized study was conducted at 13 Middle Eastern centers. After de novo CRT-D implant (Abbott Unify Quadra MP or Quadra Assura MP) with quadripolar LV lead (Abbott Quartet), patients were randomized to either BiV or MPP therapy. In BiV patients, the LV pacing vector was selected per standard practice; in MPP patients, the two LV pacing vectors were selected automatically using VectSelect. CRT response was defined at 6 months post-implant by a reduction in LV end-systolic volume (ESV) [?]15\%. 
Results : One-hundred and forty-two patients (61 years old, $68 \%$ male, NYHA class II/III/IV $19 \% / 75 \% / 6 \%, 33 \%$ ischemic, $57 \%$ hypertension, $52 \%$ diabetes, $158 \mathrm{~ms}$ QRS, $25.8 \%$ ejection fraction [EF]) were randomized to either $\mathrm{BiV}(\mathrm{N}=69)$ or MPP $(\mathrm{N}=73)$. After 6 months, MPP vs. BiV patients experienced greater ESV reduction (25.0\% vs. $15.3 \%, \mathrm{P}=0.08)$, greater $\mathrm{EF}$ elevation ( $11.9 \%$ vs. 8.6\%, $\mathrm{P}=0.36)$, significantly greater ESV response rate $(68.5 \%$ vs. $50.7 \%, \mathrm{P}=0.04)$, and significantly greater NYHA class improvement rate ( $80.8 \%$ vs. $60.3 \%, \mathrm{P}=0.01)$.

Conclusions : With MPP and automatic LV vector selection, more CRT patients in the Middle East experienced reverse remodeling and clinical improvement relative to conventional $\mathrm{BiV}$ pacing.

Keywords: Cardiac resynchronization therapy; heart failure; reverse remodeling; multipoint pacing

\section{Introduction}

Cardiac resynchronization therapy (CRT) provides significant long-term benefits to patients with moderate to severe heart failure (HF), prolonged QRS duration, and reduced ejection fraction (EF). ${ }^{1-3}$ However, up to $40 \%$ of patients fail to clinically respond to conventional CRT. ${ }^{4,5}$ Multipoint left ventricular (LV) pacing (MultiPoint Pacing [MPP], Abbott, Sylmar, CA), stimulating two LV sites on a quadripolar lead, is one key strategy to improve CRT response over conventional biventricular (BiV) pacing.

Head-to-head comparisons have demonstrated improvements of MPP over BiV in terms of LV pressure response $^{6-9}, \mathrm{LV}$ peak radial strain ${ }^{10}, \mathrm{LV}$ electrical activation ${ }^{11}$, and long-term LV function ${ }^{12-15}$. The benefits of the additional LV pacing vector, however, come with the burden of additional programming options. In MPP clinical studies to date, selection of the two LV pacing vectors (each with up to $14 \mathrm{LV}$ cathode-anode combinations) has either (1) been guided by manual, in-clinic electrical or hemodynamic measurements, or (2) left entirely to the discretion of the physician. Consequently, any clinical improvement ultimately observed cannot be directly associated with a single, consistent programming guideline that can be implemented routinely in-clinic. The current study is the first randomized comparison of MPP and BiV in the Middle East that relied solely on one automated, programmer-based tool (VectSelect ${ }^{\mathrm{TM}}$, Abbott) which provides MPP LV pacing vector recommendations that are both patient-specific and require minimal physician input.

In this prospective, multi-center investigation, patients were implanted with CRT-D devices and randomized to receive either BiV pacing or MPP. Patient response to CRT was quantified after 6 months by reductions in LV end-systolic volume (ESV) and elevations in LV ejection fraction (EF), both indicative of a reversal of the LV dilation and dysfunction associated with heart failure (i.e., LV reverse remodeling).

\section{Methods}

\section{Study Population}

To be enrolled, patients must have been at least 18 years of age, able to provide informed consent, and indicated for de novo CRT-D device implantation. Patients were excluded who did not exhibit left bundle branch block (LBBB), had an epicardial ventricular lead system implanted, exhibited an intrinsic atrial rate below $40 \mathrm{bpm}$, exhibited atrial fibrillation (AF), had a life expectancy less than 1 year, were pregnant, or dependent on IV inotropic agents. Patients were classified as exhibiting AF if it was either (i) persistent, (ii) permanent and not treated with AV node ablation within 2 weeks of CRT implant, or (iii) documented as paroxysmal or persistent within 30 days of enrollment. 


\section{Study Design}

This prospective, chronic, randomized, international study was conducted at 13 centers in the Middle East: National Guard Hospital (Riyadh, KSA), King Fahad Armed Forces Hospital (Jeddah, KSA), Prince Sultan Cardiac Center (Riyadh, KSA), Royal Hospital (Muscat, Oman), Ibn Al-Bitar Cardiac Center (Baghdad, Iraq), Nasiriya Heart Center (Nasiriya, Iraq), King Khalid University Hospital (Riyadh, KSA), King Faisal Hospital and Research Center (Riyadh, KSA), Bahrain Defense Force Hospital (Manama, Bahrain), Aswan Heart Centre (Aswan, Egypt), King Abdulaziz University Hospital (Jeddah, KSA), Cleveland Clinic Abu Dhabi (Abu Dhabi, UAE), and Sabah Al-Ahmad Cardiac Center (Kuwait City, Kuwait). All patients provided informed consent, and all study protocols were approved by the ethics committee of each institution.

Enrolled patients were implanted with a de novo CRT-D device (Abbott Unify Quadra MP or Quadra Assura MP) and quadripolar LV lead (Abbott Quartet) according to standard practice. Prior to hospital discharge, patients were randomized into one of two treatment groups, as follows.

1. BiV Group : devices programmed to conventional BiV pacing, with the single LV pacing vector selected according to the standard practice of the implanting physician.

2. MPP Group : devices programmed with MPP enabled, with the two LV pacing vectors (LV1, LV2) selected using the automatic VectSelect ${ }^{\mathrm{TM}}$ feature. Specifically, the VectSelect feature was used to assign LV1 and LV2 cathodes to the LV electrodes with the earliest and latest RV-LV conduction times (RV-sensed to LV-sensed), respectively, with corresponding anodes assigned to yield capture thresholds less than $3.5 \mathrm{~V}$ with no phrenic nerve stimulation observed at an output of $1.5 \mathrm{x}$ capture threshold.

For both groups, programming of the atrioventricular delay was left to the discretion of the implanting physician. For BiV, the interventricular delay was set to the default value (LVRV, $10 \mathrm{~ms}$ ). For MPP, both the intraventricular and interventricular delays were set to the default values (LV1LV2, $5 \mathrm{~ms}$; LV2RV, $5 \mathrm{~ms}$ ).

Echocardiography and 12-lead surface electrocardiography were performed at implant and repeated 6 months post-implant. Echocardiographic metrics were analyzed by blinded core labs. ECG QRS duration (QRSd) was defined as the time from the earliest start-time (departure from isoelectric) to the latest end-time (return to isoelectric) across all ECG leads, following standard recommendations and ignoring any pre-QRS deflections attributed to pacing artifacts. ${ }^{16}$

\section{Study Endpoints}

CRT response was characterized by changes in LV end-systolic volume ( $\triangle \mathrm{ESV})$ and LV ejection fraction $(\triangle \mathrm{EF})$ at 6 months post-implant. Patients were classified as ESV responders if they demonstrated a relative reduction in ESV of at least $15 \%$ vs. baseline. The primary endpoint of the study was a comparison of the proportion of ESV responders (i.e., ESV responder rate) between the BiV and MPP groups. In addition, a combined $\mathrm{ESV}+\mathrm{EF}$ response classification was also used, in which patients were classified as ESV+EF responders if they demonstrated both a relative reduction in ESV of at least $10 \%$ and an absolute elevation in EF of at least $5 \%$ vs. baseline. ${ }^{17}$ Secondary endpoints included the following comparisons between BiV and MPP groups: ESV reduction, EF elevation, QRS duration (QRSd) reduction, ESV+EF responder rate, and improvement in NYHA functional class.

\section{Statistical Analysis}

Statistical analyses were performed using Matlab (Statistics Toolbox, The Mathworks). Categorical variables were reported by patient count and patient percentage. Differences in categorical variables between groups were tested using Fisher's exact test. Continuous variables were reported as median and interquartile range (IQR), as none demonstrated standard normal distributions according to one-sample Kolmogorov-Smirnov tests. Differences in continuous variables between groups were tested using the Mann-Whitney U test. The 
impact of baseline characteristics on ESV responder rates was quantified using binomial regression. For all statistical tests, $\mathrm{P}<0.05$ was considered statistically significant.

\section{Results}

\section{Baseline Characteristics}

One-hundred and eighty-two (182) patients were enrolled in 13 centers across 7 Middle Eastern countries. LV lead implantation was unsuccessful in $8(4.4 \%)$ patients, $4(2.2 \%)$ withdrew from the study post-implant, lead dislodgement or system explant occurred in $3(1.7 \%), 3$ (1.7\%) experienced non-cardiac related death, echocardiography was incomplete in $2(1.1 \%)$, and 20 (18.4\%) were lost to follow-up. Ultimately, 142 patients contributed complete datasets, with 69 and 73 patients randomized to the BiV and MPP groups, respectively. Baseline patient characteristics were similar for across both groups and are provided in Table 1.

The distributions of RA, RV, and LV lead locations are provided in Figure 1. RA and RV leads were predominantly placed in the RA appendage $(97.8 \%)$ and RV apex (85.7\%), respectively. From base-toapex, LV leads were predominantly placed medially $(76.1 \%)$, and from anterior-posterior, LV leads were predominantly placed postero-laterally $(58.5 \%)$ or laterally $(39.4 \%)$.

The distribution of programmed LV cathodes in the BiV group and programmed LV1 and LV2 cathodes in the MPP group are shown in Figure 2. The most common LV cathode programmed for BiV patients was D1 (49\% of patients). The most common LV1 and LV2 cathodes programmed for MPP patients were D1 (65\%) and M3 (32\%), respectively. Correspondingly, the most common LV1/LV2 cathode pairs in MPP patients were D1/M3 (24\%), D1/M2 (22\%), and D1/P4 (19\%). The LV1/LV2 cathode pairs were associated with an anatomical separation $>30 \mathrm{~mm}$ in $61 \%$ of MPP patients.

\section{CRT Response Rate}

The MPP group demonstrated higher 6-month CRT responder rates than the BiV group, as shown in Figure 3. The proportion of patients demonstrating an ESV reduction of $15 \%$ or greater was significantly higher in the MPP group $(68.5 \%, 50 / 73)$ than in the $\operatorname{BiV}$ group $(50.7 \%, 35 / 69, \mathrm{P}=0.04)$. The proportion of patients demonstrating an ESV reduction of $30 \%$ or greater (i.e., "super-responders") was also higher in the MPP group $(39.7 \%, 29 / 73)$ than in the BiV group $(27.5 \%, 19 / 69, \mathrm{P}=0.16)$. In terms of the combined ESV and EF response criteria, the proportion of patients demonstrating an ESV reduction of at least $10 \%$ in conjunction with an EF elevation of at least $5 \%$ was significantly higher in the MPP group $(65.8 \%, 48 / 73)$ than in the $\mathrm{BiV}$ group $(44.9 \%, 31 / 69, \mathrm{P}=0.02)$.

\section{Reverse Remodeling}

The LV reverse remodeling effects of CRT are shown in Figure 4. Patients in the MPP group experienced a greater reduction in ESV (median $[\mathrm{IQR}]=25.0 \%[11.5 \%, 37.2 \%]$ ) than patients in the BiV group (15.3\% $[3.3 \%, 31.3 \%], \mathrm{P}=0.08)$. Likewise, patients in the MPP group experienced greater EF elevations $(11.9 \%$ $[5.5 \%, 19.7 \%])$ than patients in the $\mathrm{BiV}$ group $(8.6 \%[3.7 \%, 16.9 \%], \mathrm{P}=0.36)$.

\section{Electrical Synchrony}

The impact of CRT on alleviating electrical dyssynchrony can be quantified by changes in QRS duration, also shown in Figure 4. At 6 months post-implant, patients in the MPP group experienced greater QRS duration narrowing than patients in the $\mathrm{BiV}$ group $(15.1 \%[4.1,26.0]$ vs. $13.3 \%[2.5,20.9], \mathrm{P}=0.17)$. 


\section{NYHA Functional Class}

At 6 months post-implant, significantly more patients in the MPP group experienced an improvement in NYHA functional class $(80.8 \%, 59 / 73)$ than those in the BiV group $(60.3 \%, 41 / 68, \mathrm{P}=0.01)$, as shown in Figure 5. Furthermore, more patients in the MPP group improved by at least 2 NYHA functional class levels $(28.8 \%, 21 / 73)$ than those in the $\mathrm{BiV}$ group $(16.2 \%, 11 / 68, \mathrm{P}=0.11)$.

\section{Impact of Baseline Characteristics on Response}

The potential use of baseline characteristics as predictors of ESV response was quantified using binomial regression, with results provided in Figure 6. For patients with $\mathrm{BiV}$ therapy, ischemic cardiomyopathy significantly reduced the odds of ESV response $(\mathrm{P}=0.02)$, while age $(\mathrm{P}=0.06)$ and poor NYHA class $(\mathrm{P}=0.05)$ both approached significance. In contrast, those factors were not predictive of response to MPP. For MPP patients, only gender was a significant predictor $(\mathrm{P}=0.01)$. In the MPP group, male patients made up $54.0 \%$ of responders, but $91.3 \%$ of non-responders.

\section{Discussion}

By properly synchronizing both right and left ventricular contraction, CRT can reverse the progressive LV dilation (i.e., remodeling) associated with heart failure, improving systolic/diastolic function and, subsequently, clinical outcomes. By adding a second LV pacing site, MultiPoint Pacing has demonstrated promising longterm improvements over conventional biventricular $\mathrm{CRT}^{12-15}$. Due to the added programming flexibility of a second LV vector, most MPP devices are left unoptimized with out-of-the-box settings. For CRT implanting centers to achieve the response rates reported by early MPP studies, programming protocols are recommended that often require time-consuming in-clinic measurements.

In the first randomized, multi-center MPP investigation conducted entirely in the Middle East, patients were implanted with CRT-D devices and randomized to receive either BiV or MPP therapy. While LV vector selection in the $\mathrm{BiV}$ group was left to the discretion of the implanting physician, the VectSelect ${ }^{\mathrm{TM}}$ programmer tool (Abbott) was used to automatically recommend LV vectors for the MPP group, with no external measurements and minimal physician input.

VectSelect recommends MPP LV pacing vectors based on automatic capture threshold and RV-LV conduction time measurements. VectSelect provides two recommendation options for MPP LV cathode pairs: (1) the electrodes with maximal anatomical separation, and (2) the earliest- and latest-activating electrodes. Largescale clinical trials have previously shown improved response to MPP when LV vectors were selected with $>30 \mathrm{~mm}$ anatomical spacing, relative to other MPP configurations ${ }^{18,19}$. However, the clinical outcomes associated with this strategy were only retrospectively evaluated, leaving it unclear if the vector selection was actually the result of other forms of optimization. Furthermore, the maximal separation option for most leads requires availability of the proximal electrode for $>30 \mathrm{~mm}$ separation, which typically has higher capture thresholds. The current study is the first prospective comparison of MPP and BiV that relied solely on the VectSelect ${ }^{\mathrm{TM}}$ programmer tool (Abbott) to automatically recommend MPP LV pacing vectors using the earliest- and latest-activating electrode option.

Relative to patients receiving conventional BiV therapy, a significantly higher proportion of MPP patients demonstrated an ESV reduction of $15 \%$ or more (primary endpoint), and a significantly higher proportion of MPP patients experienced an improvement in NYHA functional class. Changes in ESV, EF, and QRSd all trended toward greater improvement in MPP patients than BiV patients, although statistical significance was not reached in this study for these three metrics. Together, these results point to the enhanced functional and clinical benefits of MPP.

Similar comparisons of MPP and BiV have been reported, but differed in patient population, LV vector selection strategy, and inter-/intra-ventricular delay programming. In a single-center, 44-patient study, 
Pappone et al. ${ }^{12}$ reported 12 -month MPP vs. BiV responder rates for ESV reduction ( $\left.\Delta \mathrm{ESV}[?] \quad 15 \%\right)$ of $76 \%$ vs. $57 \%$, and for NYHA class improvement of $90 \%$ vs. $84 \%$, respectively. While these rates were slightly higher than those observed here (68.5\% vs. $50.7 \%$ for ESV; $80.8 \%$ vs. $60.3 \%$ for NYHA), the study by Pappone et al. included LV vector and inter-/intra-ventricular delay optimization based on comprehensive acute hemodynamic measurements (invasive $\mathrm{dP} / \mathrm{dt}_{\max }$ ), rather than leveraging automated $\mathrm{LV}$ vector selection tools and maintaining nominal (i.e., minimal) inter-/intra-ventricular delays.

In a retrospective study of 110 CRT patients with optimized LV pacing sites at a single Italian center, Zanon et al. ${ }^{15}$ reported higher 12 -month MPP vs. BiV responder rates in terms of ESV reduction (90\% vs. $72 \%$ ) and NYHA class improvement (95\% vs. $78 \%$ ). These rates were also slightly higher than this report, even though inter-/intra-ventricular delays were left at nominal values and not optimized. However, the target LV vein was selected based on manually optimization of either Q-LV time or invasive hemodynamics, with an average of 3 veins tested per patient. In a larger prospective study of 232 patients in 76 Italian centers, Forleo et al. ${ }^{13}$ showed 6 -month EF elevations with MPP vs. BiV (10.7\% vs. $\left.6.5 \%\right)$ that were comparable to those reported here (11.9\% vs. $8.6 \%)$. Still, MPP LV pacing vector selection was not standardized among centers, and included both QRS optimization and maximization of electrical delays between cathodes.

With varied and often time-consuming programming strategies, these research studies were not designed to identify a simple, efficient MPP programming guideline for broad clinical application. Furthermore, all the aforementioned studies were limited to Italian centers, and the results may not be directly applicable worldwide. Not only can the results of the current study be more readily applied to patients in the Middle East, but they may be achievable with minimal physician intervention and without costly or lengthy optimization protocols. Moreover, the reverse modeling response to MPP using VectSelect in this population was not contingent upon commonly cited baseline predictors, such as age, poor NYHA class, long QRSd, low EF, or negative comorbidities (e.g. ischemic cardiomyopathy, hypertension, diabetes), further highlighting its broad application.

The 6-month impact of MPP demonstrated in this study may also point to longer-term benefits. A recent analysis of 436 CRT patients by Rickard et al. ${ }^{17}$ evaluated the ability of early echocardiographic changes (9-month echocardiographic follow-up time) to predict longer-term outcomes (5-year clinical follow-up time). Of commonly used reverse left ventricular remodeling metrics (i.e., end-systolic volume, end-diastolic volume, ejection fraction) with various benchmarks, the analysis identified the combined criteria of ESV reduction by $10 \%$ and EF elevation by $5 \%$ as the most appropriate predictor of patient survival without an LV assist device (LVAD) or heart transplant. According to this response metric, significantly more MPP than BiV patients in this Middle Eastern population (65.8\% vs. $44.9 \%$ ESV+EF responders) are predicted to survive long-term without requiring more serious intervention.

\section{Limitations}

Although LV vector selection, intraventricular delay, and interventricular delay were all defined a priori for MPP patients, this study left the atrioventricular delay to the physician's discretion. Consequently, the functional and clinical benefits associated with MPP in this study cannot be attributed to a specific, comprehensive programming strategy. Similarly, for BiV patients, both the atrioventricular delay and LV vector selection were left to the discretion of the implanting physician. A more direct comparison of MPP vs. BiV would require standardized AVD optimization methods and may yield different results.

\section{Conclusions}

In the Middle East, more CRT patients experienced reverse remodeling and clinical improvement with MPP over conventional biventricular pacing when using automatic MPP vector selection. 


\section{Members of the Quadra MPP ME Group}

Members of the Quadra MPP ME Group include Abdelrahman Jamiel, MD ${ }^{1}$; Amjad Al-Mandalawi, MD ${ }^{2}$; Mohamed Hashim, MD ${ }^{3}$; Mohammad Amin, $\mathrm{MD}^{4}$; Mohamed ElMaghawry, $\mathrm{MD}^{5}$; Antonio Sorgente, $\mathrm{MD}^{6}$; Maria Loricchio, $\mathrm{MD}^{7}$; Ghaliah AlMohani, $\mathrm{MD}^{8}$; Ismail Al Abri, $\mathrm{MD}^{8}$; Edmon Benjamin, $\mathrm{MD}^{2}$; Nazar Sudan, $\mathrm{MD}^{3}$; Alexandre Chami, CCRP ${ }^{9}$ Nima Badie, $\mathrm{PhD}^{10}$; and Mohammed Sayed, $\mathrm{MD}^{5}$.

1. King Abdulaziz Medical City - National Guard Health Affairs, Riyadh, Kingdom of Saudi Arabia

2. Ibn Al-Bitar Cardiac Center, Baghdad, Iraq

3. Nasiriya Heart Center, Nasiriya, Iraq

4. Bahrain Defense Force Hospital, Manama, Bahrain

5. Aswan Heart Centre, Aswan, Egypt

6. Cleveland Clinic Abu Dhabi, Abu Dhabi, UAE

7. Sabah Al-Ahmad Cardiac Center, Kuwait City, Kuwait

8. National Heart Center at the Royal Hospital, Muscat, Oman

9. Abbott, Dubai, UAE

10. Abbott, Sunnyvale, CA, USA

\section{References}

1. Sutton MGS, Plappert T, Abraham WT, Smith AL, DeLurgio DB, Leon AR, Loh E, Kocovic DZ, Fisher WG, Ellestad M, Messenger J, Kruger K, Hilpisch KE, Hill MRS, Grp MS. Effect of cardiac resynchronization therapy on left ventricular size and function in chronic heart failure.Circulation . 2003;107:1985-1990.

2. Cazeau S, Leclercq C, Lavergne T, Walker S, Varma C, Linde C, Garrigue S, Kappenberger L, Haywood GA, Santini M, Bailleul C, Daubert JC. Effects of multisite biventricular pacing in patients with heart failure and intraventricular conduction delay. NEnglJMed . 2001;344:873-880.

3. Abraham WT, Fisher WG, Smith AL, Delurgio DB, Leon AR, Loh E, Kocovic DZ, Packer M, Clavell AL, Hayes DL, Ellestad M, Trupp RJ, Underwood J, Pickering F, Truex C, McAtee P, Messenger J, Evaluation MSGMIRC. Cardiac resynchronization in chronic heart failure. N Engl J Med . 2002;346:1845-1853.

4. Fornwalt BK, Sprague WW, BeDell P, Suever JD, Gerritse B, Merlino JD, Fyfe DA, Leon AR, Oshinski JN. Agreement is poor among current criteria used to define response to cardiac resynchronization therapy.Circulation . 2010;121:1985-1991.

5. Tolosana JM, Mont L. Cardiac Resynchronization Therapy - How to Decrease Nonresponders. Heart Fail Clin . 2017;13:233-240.

6. Thibault B, Dubuc M, Khairy P, Guerra PG, Macle L, Rivard L, Roy D, Talajic M, Karst E, Ryu K, Paiement P, Farazi TG. Acute haemodynamic comparison of multisite and biventricular pacing with a quadripolar left ventricular lead. Europace . 2013;15:984-991.

7. Pappone C, Calovic Z, Vicedomini G, Cuko A, McSpadden LC, Ryu K, Romano E, Saviano M, Baldi M, Pappone A, Ciaccio C, Giannelli L, Ionescu B, Petretta A, Vitale R, Fundaliotis A, Tavazzi L, Santinelli V. Multipoint left ventricular pacing improves acute hemodynamic response assessed with pressure-volume loops in cardiac resynchronization therapy patients. Hear Rhythm . 2014;11:394-401.

8. Zanon F, Baracca E, Pastore G, Marcantoni L, Fraccaro C, Lanza D, Picariello C, Aggio S, Roncon L, Dell'Avvocata F, Rigatelli G, Pacetta D, Noventa F, Prinzen FW. Multipoint pacing by a left ventricular 
quadripolar lead improves the acute hemodynamic response to CRT compared with conventional biventricular pacing at any site. Hear Rhythm . 2015;12:975-981.

9. Lercher P, Lunati M, Rordorf R, Landolina M, Badie N, Qu F, Casset C, Ryu K, Ghio S, Singh JP, Leclercq C. Long-term reverse remodeling by cardiac resynchronization therapy with MultiPoint Pacing: A feasibility study of noninvasive hemodynamics-guided device programming. Hear Rhythm . 2018;15. doi:10.1016/j.hrthm.2018.06.032.

10. Osca J, Alonso P, Cano O, Andres A, Miro V, Tello MJ, Olague J, Martinez L, Salvador A. The use of multisite left ventricular pacing via quadripolar lead improves acute haemodynamics and mechanical dyssynchrony assessed by radial strain speckle tracking : initial results. Europace . 2016;18:560-567.

11. Menardi E, Ballari GP, Goletto C, Rossetti G, Vado A. Characterization of ventricular activation pattern and acute hemodynamics during multipoint left ventricular pacing. Hear Rhythm . 2015;12:1762-1769.

12. Pappone C, Calovic Z, Vicedomini G, Cuko A, McSpadden LC, Ryu K, Jordan CD, Romano E, Baldi M, Saviano M, Pappone A, Vitale R, Catalano C, Ciaccio C, Giannelli L, Ionescu B, Petretta A, Fragakis N, Fundaliotis A, Tavazzi L, Santinelli V. Improving cardiac resynchronization therapy response with multipoint left ventricular pacing: Twelve-month follow-up study. Hear Rhythm . 2015;12:1250-1258.

13. Forleo GB, Santini L, Giammaria M, Potenza D, Curnis A, Calabrese V, Ricciardi D, D'Agostino C, Notarstefano P, Ribatti V, Morani G, Mantica M, Di Biase L, Bertaglia E, Calo L, Zanon F. Multipoint pacing via a quadripolar left-ventricular lead: preliminary results from the Italian registry on multipoint left-ventricular pacing in cardiac resynchronization therapy (IRON-MPP). Europace . 2017;19:1170-1177.

14. Zanon F, Marcantoni L, Baracca E, Pastore G, Lanza D, Aggio S, Roncon L, Conte L, Picariello C, Carraro M, Noventa F, Prinzen FW. Optimization of left ventricular pacing site plus multipoint pacing improves remodeling and clinical response to cardiac resynchronization therapy at 1 year. Hear Rhythm . 2016;13:1644-1651.

15. Zanon F, Marcantoni L, Baracca E, Pastore G, Lanza D, Fraccaro C, Picariello C, Conte L, Aggio S, Roncon L, Pacetta D, Badie N, Noventa F, Prinzen FW. Optimization of left ventricular pacing site plus multipoint pacing improves remodeling and clinical response to cardiac resynchronization therapy at 1 year. Hear Rhythm . 2016;13:1644-1651.

16. Surawicz B, Childers R, Deal BJ, Gettes LS, Bailey JJ, Gorgels A, Hancock EW, Josephson M, Kligfield P, Kors JA, Macfarlane P, Mason JW, Mirvis DM, Okin P, Pahlm O, Rautaharju PM, van Herpen G, Wagner GS, Wellens H. AHA/ACCF/HRS recommendations for the standardization and interpretation of the electrocardiogram: part III: intraventricular conduction disturbances: a scientific statement from the American Heart Association Electrocardiography and Arrhythmias Committee,.Circulation . 2009;119:e23540.

17. Rickard J, Baranowski B, Wilson Tang WH, Grimm RA, Niebauer M, Cantillion D, Wilkoff BL, Varma N. Echocardiographic Predictors of Long-Term Survival in Patients Undergoing Cardiac Resynchronization Therapy: What Is the Optimal Metric? J Cardiovasc Electrophysiol . 2017;28:410-415.

18. Leclercq C, Burri H, Curnis A, Delnoy PP, Rinaldi CA, Sperzel J, Lee K, Calò L, Vicentini A, Concha JF, Thibault B. Cardiac resynchronization therapy non-responder to responder conversion rate in the more response to cardiac resynchronization therapy with MultiPoint Pacing (MORE-CRT MPP) study: Results from Phase i. Eur Heart J . 2019. doi:10.1093/eurheartj/ehz109.

19. Niazi I, Baker II J, Corbisiero R, Love C, Martin D, Sheppard R, Worley S, Varma N, Lee K, Tomassoni G. Safety and Efficacy of Multipoint Pacing in Cardiac Resynchronization Therapy. JACC Clin Electrophysiol . 2017;3:1519-1522.

Tables 
Table 1. Baseline characteristics, shown for all patients, biventricular pacing (BiV) patients, and MultiPoint Pacing (MPP) patients. P values demonstrate differences between BiV and MPP groups.

\begin{tabular}{lllll}
\hline Characteristic & All Patients & BiV & MPP & P (BiV vs. MPP) \\
Sample size, n (\%) & $142(100.0 \%)$ & $69(48.6 \%)$ & $73(51.4 \%)$ & \\
Male, n (\%) & $96 / 142(67.6 \%)$ & $48 / 69(69.6 \%)$ & $48 / 73(65.8 \%)$ & 0.720 \\
Age, yr & $61.2[52.3,67.9]$ & $59.6[52.1,67.0]$ & $62.1[52.3,69.4]$ & 0.251 \\
NYHA, n (\%) & & & 0.186 \\
I & $0 / 142(0.0 \%)$ & $0 / 69(0.0 \%)$ & $0 / 73(0.0 \%)$ & \\
II & $27 / 142(19.0 \%)$ & $16 / 69(23.2 \%)$ & $11 / 73(15.1 \%)$ & \\
III & $107 / 142(75.4 \%)$ & $50 / 69(72.5 \%)$ & $57 / 73(78.1 \%)$ & \\
IV & $8 / 142(5.6 \%)$ & $3 / 69(4.3 \%)$ & $5 / 73(6.8 \%)$ & \\
Ischemic, n (\%) & $47 / 142(33.1 \%)$ & $21 / 69(30.4 \%)$ & $26 / 73(35.6 \%)$ & 0.593 \\
Hypertension, n (\%) & $81 / 142(57.0 \%)$ & $34 / 69(49.3 \%)$ & $47 / 73(64.4 \%)$ & 0.090 \\
Diabetes, n (\%) & $74 / 142(52.1 \%)$ & $39 / 69(56.5 \%)$ & $35 / 73(47.9 \%)$ & 0.319 \\
QRS duration, ms & $158.0[150.0,170.0]$ & $158.0[150.0,170.0]$ & $160.0[150.0,172.3]$ & 0.434 \\
LVESV, mL & $135.0[102.0,200.0]$ & $140.0[102.0,191.0]$ & $130.0[103.0,206.0]$ & 1.000 \\
LVEDV, mL & $185.5[148.0,265.0]$ & $185.0[163.8,250.0]$ & $188.0[145.0,274.0]$ & 0.920 \\
LVSV, mL & $50.0[39.0,61.0]$ & $50.0[40.0,60.3]$ & $49.0[37.3,63.5]$ & 0.612 \\
LVEF, \% & $25.8[21.2,33.3]$ & $25.7[21.7,32.5]$ & $26.0[21.1,33.6]$ & 0.922 \\
\hline
\end{tabular}

\section{Figures}

Figure 1. Distribution of implant locations for right atrial (RA), right ventricular (RV), and left ventricular (LV) leads (base-apex, anterior-posterior), as percent of all patients.

\section{Hosted file}

image1.emf available at https://authorea.com/users/322025/articles/451138-long-term-reverseremodeling-and-clinical-improvement-by-multipoint-pacing-in-a-randomized-internationalmiddle-eastern-heart-failure-study

Figure 2. Distribution left ventricular (LV) pacing vector cathodes for biventricular pacing (BiV, left) and MultiPoint Pacing (MPP, right) groups. D1/M2/M3/P4 cathodes correspond to Distal Tip 1, Mid 2, Mid 3, Proximal 4.

\section{Hosted file}

image2.emf available at https://authorea.com/users/322025/articles/451138-long-term-reverseremodeling-and-clinical-improvement-by-multipoint-pacing-in-a-randomized-internationalmiddle-eastern-heart-failure-study

Figure 3. End-systolic volume (ESV) response distribution (top), detailed ESV response distribution (middle), and end-systolic volume + ejection fraction (ESV+EF) response distribution (bottom) for biventricular $(\mathrm{BiV})$ and MultiPoint Pacing (MPP) patients.

\section{Hosted file}

image3.emf available at https://authorea.com/users/322025/articles/451138-long-term-reverseremodeling-and-clinical-improvement-by-multipoint-pacing-in-a-randomized-internationalmiddle-eastern-heart-failure-study

Figure 4. End-systolic volume reduction ( $\triangle \mathrm{ESV}$, left), ejection fraction elevation ( $\triangle \mathrm{EF}$, center), and QRS duration reduction $(\Delta \mathrm{QRSd}$, right) for biventricular $(\mathrm{BiV})$ and MultiPoint Pacing (MPP) patients after 6 months. 


\section{Hosted file}

image4.emf available at https://authorea.com/users/322025/articles/451138-long-term-reverseremodeling-and-clinical-improvement-by-multipoint-pacing-in-a-randomized-internationalmiddle-eastern-heart-failure-study

Figure 5. Distribution of changes in NYHA functional class for biventricular (BiV) and MultiPoint Pacing (MPP) patients after 6 months.

\section{Hosted file}

image5.emf available at https://authorea.com/users/322025/articles/451138-long-term-reverseremodeling-and-clinical-improvement-by-multipoint-pacing-in-a-randomized-internationalmiddle-eastern-heart-failure-study

Figure 6. Impact of baseline characteristics on end-systolic volume (ESV) responder rate odds ratio (OR) for biventricular (BiV) and MultiPoint Pacing (MPP) patients, as evaluated by binomial regression.

\section{Hosted file}

image6.emf available at https://authorea.com/users/322025/articles/451138-long-term-reverseremodeling-and-clinical-improvement-by-multipoint-pacing-in-a-randomized-internationalmiddle-eastern-heart-failure-study 